Background In line with a consistent literature, somatic symptom disorders (having pronounced somatic symptoms without objective somatic signs) in childhood and adolescence have experienced traumatic events, such as physical or sexual abuse, major loss, natural disasters or who have been witnesses to violence. Recent studies are focusing the attention on the role of attachment and post-traumatic symptomatology for a better evaluation of this disorder.

Objective The following objectives are set by the present study: 1) to evaluate the post-traumatic stress and related psychological symptomatology in a group of children diagnosed with somatic symptom disorders; 2) to evaluate their attachment models; 3) to test the extent of the association between post-traumatic symptomatology and attachment organisation in somatic symptom disorders.

Method Twenty consecutive Italian patients aged from 8 to 15 $(\mathrm{m}=11,9 ; \mathrm{ds}=1,48)$, previously diagnosed with somatic symptom disorders, were administered the Trauma Symptom Checklist for Children (TSCC-A) and the Child Attachment Interview (CAI).

Results Post-traumatic symptomatology, evaluated in 9 subscales, showed clinically significant scores about anxiety, depression and post-traumatic stress; dissociation symptomatology was seen only in $5 \%$ of the patients. Insecure attachment was found in more than half of the patients diagnosed with somatic symptom disorders.

Conclusions This study suggests that attachment organisation may be a fundamental element to be assessed in the evaluation of somatic symptom disorders in children and adolescents. Finally, methodological limitations restricting causal inferences between attachment and dissociation are discussed.

\section{P0-0940 INFLUENCE OF FERROTHERAPY ON PSYCHOMOTOR DEVELOPMENT OF CHILDREN OF YEARLY AGE WITH IRON DEFICIENCY ANAEMIA}

${ }^{1} \mathrm{~K}$ MatiaSvili, ${ }^{2} \mathrm{~N}$ Manjavidze, ${ }^{3} \mathrm{~T}$ Ghongadze, ${ }^{2} \mathrm{~N}$ Adamia, ${ }^{2} \mathrm{M}$ Ghughunishvili. ${ }^{1} \mathrm{M}$. lashvili Children's Central Hospital, Department of General Pediatrics, Tbilisi, Georgia; ${ }^{2}$ Tbilisi State Medical University, Tbilisi, Georgia; ${ }^{3}$ I. Tsitsisshvili Children Hospital, Department of General Pediatrics, Tbilisi, Georgia

10.1136/archdischild-2014-307384.1561

According to universally acknowledged biopsychosocial model of development, numerous biological and environmental factors influence development of children. One of them is iron deficiency in the organism. The study assessed physical, motor and psychosocial development of children who at an early age had the diagnosis of iron deficiency anaemia and had been treated by iron drugs. Their neurological, receptive, expressive and cognitive functions were assessed using BINS (Bayeley's Infanft's Neurodevelopmental Screen). The sample was divided into 2 age groups: 16-20 and 21-24 months.

The study shows that in children, who had iron deficiency at an early age and had taken treatment with relevant drugs in a timely manner, the aggregate indicators of four clusters do not differ significantly from standard indicators submitted by BINS. We deem important time diagnosis of iron deficiency and beginning of respective treatment, in order to avoid problems in psychomotor development; Timely treatment will favour the processes of development of child's social and school preparedness.

\section{PO-0941 THE CAUSES OF PSYCHOSOMATIC DISORDERS IN CHILDREN}

${ }^{1} \mathrm{~N}$ Makieieva, ${ }^{1} \mathrm{~A}$ Penkov, ${ }^{1} \mathrm{R}$ Marabyan, ${ }^{2} \mathrm{M}$ Kholodova, ${ }^{2}$ Vasheva. ${ }^{1}$ Pediatrics \#1 and Neonatology, Kharkov National Medical University, Kharkov, Ukraine; ${ }^{2}$ Neurology, Kharkov Region Children's Clinical Hospital, Kharkov, Ukraine

10.1136/archdischild-2014-307384.1562

Background and aims The causes of psychosomatic disorders in children are in a family attitude towards a child and the relationship between parents. The understanding of 'family psychological health' will allow creating strategies to prevent and treat psychosomatic disorders in children.

Aims To define the types of family disorganisation and psychological adaptation features of preschoolers living in families.

Methods The questioning on the test ' $\mathrm{ABC}$ for parents and children aged 3-10 years' the parents of 36 preschoolers with psychosomatic symptoms was held. We studied the level of parental protection in upbringing, the degree of the child's needs satisfaction, the number and quality requirements to the child in a family, instability of parenting style. The daily urine free cortisone concentrations were investigated.

Results The upbringing peculiarities which promote to deviation's development in behaviour and psychosomatic diseases development were found in $91,6 \%$ of children: due to hyperprotection (in 52,8\%) and hypoprotection (in 38,8\%). The hyperprotection of children is related to the expansion of parental feelings (56\%), upbringing insecurities of parents (61\%). In half of the families there is a projection of undesirable qualities of the parents to the child. The elevation of daily urine free cortisone excretion in children with hypoprotection compared with hyperprotection were determined $((18.2(16.0 ; 18.6)$ and 16.7 $(15.5 ; 17.7) \mathrm{nmol} / \mathrm{nmol}$ in creatinine, respectively $(\mathrm{p}<0.05))$.

Conclusions These data suggest that the paediatrician should pay attention not only to physical health of the child, but also the psychological. The timely correction of upbringing will reduce the frequency of psychosomatic illnesses.

\section{PO-0942 LEVEL OF ANXIETY IN MOTHERS WITH SICK CHILDREN APPLYING TO THE HOSPITAL IN AN OUTPATIENT SETTING}

${ }^{1} \mathrm{G}$ Daar, ${ }^{2} \mathrm{Al}$ Gül, ${ }^{3} \mathrm{H}$ Ede, ${ }^{4} \mathrm{~S}$ Polat, ${ }^{5} \mathrm{M}$ Ozdamar. ${ }^{1}$ Pediatrics, Bozok University Faculty of Medicine, Yozgat, Turkey; ${ }^{2}$ Psychiatry, Bozok University Faculty of Medicine, Yozgat, Turkey; ${ }^{3}$ Cardiology, Bozok University Faculty of Medicine, Yozgat, Turkey; ${ }^{4}$ Nursery, Bozok University School of Health Sciences, Yozgat, Turkey; ${ }^{5}$ Pediatric Surgery, Bozok University Faculty of Medicine, Yozgat, Turkey

\subsection{6/archdischild-2014-307384.1563}

Background and aims The study was aimed at searching the level of anxiety among mothers with sick children, without chronic illness in an outpatient setting by using Beck anxiety inventory (BAI) and short-health anxiety inventory (HAI) test.

Methods Mothers who brought their ill children to pediatry unit with acute complains were enrolled in the study as trial group. Mothers with children who had no illness were included in the control group drawn from out-of-hospital setting. All subjects took HAI and BAI tests. Results were analysed using SPSS programe.

Results Hundred and twelve trial subjects with average age of $32 \pm 8$ years old and 97 control subjects with average age of 31 \pm 7 years old were included in the study. There wasn't any statistically significance found between groups in respect to age ( $p$ 